\title{
СТАВЛЕННЯ ЛІКАРІВ ДО ПРОФІЛАКТИКИ НЕІНФЕКЦІЙНИХ ЗАХВОРЮВАНЬ - АДМІНІСТРАТИВНО-ТЕРИТОРІАЛЬНИЙ ЧИННИК ВПЛИВУ
}

\author{
Національний університет охорони здоров'я України імені П. Л. Шупика, м. Київ, Україна
}

Мета: охарактеризувати ставлення та діяльність лікарів стосовно здоров'я та визначити поведінкові особливості підгруп лікарів, які працюють у столиці/обласних центрах або в інших населених пунктах.

Матеріали і методи. Опитано 167 лікарів, які представляють всі макрорегіони України: визначено рівні поінорормованості про міфи щодо неінфекційних захворювань, локус контролю, погляди на ефективність профілактичних заходів, вплив на здоров'я окремих чинників оточення. Оцінку результатів здійснювали на основі даних дескриптивної статистики, статистичну вірогідність різниці показників визначали методами попарного порівняння 3 поправкою Бонфрероні та дисперсійного аналізу.

Результати. Порівняння оцінок респондентів показало нечисленні відмінності між лікарями, які працюють у м. Києві та обласних центрах (група А), та лікарями, які працюють в інших населених пунктах (група Б). Лікарі продемонстрували досить високу поінформованість про заходи профрілактики неінфекційних захворювань, водночас не завжди здійснювали практичні заходи, спрямовані на підтримку здоров'я. Відповідальність за здоров'я лікарі з обох підгруп покладали на саму особу, лікарів та близьке оточення, а найменше очікували від волонтерів, ВООЗ та преси. Опитані високо оцінили потребу дітей дотримуватися правил здорового способу життя, передусім дотримання правил безпечного сексу. Мешканці обласних центрів вважали вплив на здоров'я свого фрінансового стану та традицій у родині менш сприятливим, ніж лікарі, які живуть у решті населених пунктів.

Висновки. При порівнянні оцінки респондентами популярних тверджень щодо неінфекційних захворювань, осіб та інституцій, що несуть відповідальність за здоров'я людини, поглядів на ефрективність профілактичних заходів, впливу на здоров'я окремих чинників оточення не виявлено значних відмінностей між лікарями, які працюють у м. Києві та обласних центрах, та лікарями, які працюють у інших населених пунктах. Переоцінка респондентами складності заходів профрілактики неінфекційних захворювань свідчить про необхідність більш детального та доступного представлення спектра можливих заходів сприяння здоров'ю для ефективнішої профілактики.

КЛЮЧОВІ СЛОВА: неінфекційні захворювання; здоровий спосіб життя; безперервний професійний розвиток; соціальний маркетинг.

Згідно з дослідженнями [3, 6, 8, 11], ключовим джерелом інорормації про здоров'я в Україні та світі залишаються лікарі. Відповідно, налагодження ефективної комунікації 3 населенням стосовно профрілактики неінфекційних захворювань (НІ3) потребує поглибленого вивчення переконань та практик у сфері здоров'я самих лікарів, оскільки ці чинники можуть впливати на ефективність інформування пацієнтів про заходи профілактики НІЗ.

Виконання цього завдання вимагає розуміння умов, в яких живуть і працюють лікарі, їхніх культурних особливостей, наявних ресурсів тощо [2, 5, 7, 9, 10]. Такий підхід дозволить диференційовано підійти до фрормування пропозицій з оптимізації діяльності для кожної групи лікарів - $з$ урахуванням їхніх сильних та слабких сторін, загроз та можливостей, згідно з класичним управлінським методом SWOT-аналізу.

Мета роботи: охарактеризувати ставлення та діяльність лікарів стосовно власного здоров'я та

(c) К. В. Балашов, 2021 своїх дітей, погляди на ефрективність профрілактичних заходів, вплив на здоров'я окремих чинників оточення і визначити поведінкові особливості підгруп лікарів, які працюють у столиці та обласних центрах (група A) або в інших населених пунктах (група Б).

Матеріали і методи. 3 метою визначення ставлення і поінформованості лікарів щодо НІ3, здорового способу життя та дій, спрямованих на запобігання НІ3, проведено дослідження, деталі якого описані у [4]. На першому етапі опитано 167 лікарів, які представляють всі макрорегіони України: визначено рівні поінформованості про міфи щодо НІ3, локус контролю, погляди на ефрективність профрілактичних заходів, вплив на здоров'я окремих чинників оточення.

Визначені показники описової статистики для підгруп лікарів, які мешкають в обласних центрах і м. Києві (група А, 79 осіб) або в інших населених пунктах (група Б, 88 осіб). Визначення статистичної значущості різниці середніх показників між підгрупами здійснювали за допомогою диспер- 
сійного аналізу (ANOVA), відносних показників методів попарного порівняння 3 використанням поправки Бонфрероні. Усі статистичні процедури проводили за допомогою пакета SPSS v. 23.

Респондентів залучали з числа осіб, які брали участь у попередніх опитуваннях НМАПО імені П. Л. Шупика, та через розсилку запрошень у заклади ПМСД України. Опитувані були поінформовані, що участь у дослідженні добровільна та анонімна. Заповнення анкети здійснювали в електронній формі. Персональні дані не збирали.

Результати дослідження та їх обговорення. Демографрічні та соціальні параметри (табл. 1) досліджуваних підгруп лікарів переважно не продемонстрували статистично вірогідних відмінностей (вік, стать, частка лікарів вищої кваліфрікаційної категорії) або знайдені відмінності передбачувані: лікарі з обласних центрів істотно частіше мають вчений ступінь та працюють у приватних закладах, а їхні колеги з інших населених пунктів частіше $є$ лікарями сімейної медицини.

Цікавим фрактом $€$ істотно нижча представленість серед лікарів обласних центрів фахівців । та II лікарських категорій, що може пояснюватися легшим доступом до медичних закладів вищої освіти.

Таблиця 1. Демографрічні та соціальні параметри опитаних лікарів

\begin{tabular}{|c|c|c|c|c|c|c|c|c|c|}
\hline \multirow[b]{2}{*}{ Група } & \multirow[b]{2}{*}{$\begin{array}{c}\text { Вік, } \\
\text { роки }\end{array}$} & \multirow[b]{2}{*}{$\begin{array}{c}\text { Жінки, } \\
\%\end{array}$} & \multirow[b]{2}{*}{$\begin{array}{c}\text { Наявність } \\
\text { наукового } \\
\text { ступеня, \% }\end{array}$} & \multicolumn{3}{|c|}{ Кваліфікаційна категорія, \% } & \multicolumn{2}{|c|}{ Спеціальність, посада ${ }^{1}, \%$} & \multirow{2}{*}{$\begin{array}{c}\text { Доступ до } \\
\text { інтернету (за } \\
\text { 10-бальною } \\
\text { шкалою) } \\
\end{array}$} \\
\hline & & & & вища & $|-| \mid$ & спеціаліст & $\begin{array}{l}\text { сімейний } \\
\text { лікар }\end{array}$ & $\begin{array}{c}\text { лікар } \\
\text { приватного } \\
\text { закладу }\end{array}$ & \\
\hline A & 37,7 & 86,1 & $12,7^{*}$ & 36,4 & 13,0 * & 50,6 & 13,0 * & $18,2^{*}$ & $9,6^{\star *}$ \\
\hline Б & 40,6 & 89,8 & 2,3 & 28,4 & 30,7 & 40,9 & 33,7 & 2,3 & 9,1 \\
\hline Всього & 39,2 & 88,0 & 7,2 & 32,1 & 22,4 & 45,5 & 23,9 & 9,8 & 9,3 \\
\hline
\end{tabular}

Примітка. ${ }^{1}$ - респондентам запропоновано такі варіанти відповіді: сімейний лікар, лікар-спеціаліст поліклініки, лікар-спеціаліст стаціонару, лікар приватного сектора, медична сестра поліклініки, медична сестра стаціонару та інше; * $-p<0,05 ;$ ** $-p=0,009$.

Також лікарі з обласних центрів істотно вищим балом оцінювали свій рівень володіння англійською мовою (5,5 проти 3,8 бала у підгрупі лікарів з інших населених пунктів, p<0,001) та частоту отримання матеріалів про здоров'я 3 англомовних джерел (5,2 раза за місяць проти 1,6 раза, $\mathrm{p}=0,004)$.

Порівняння показників ставлення до здоров'я (табл. 2), зокрема курців, встановленого діагнозу НІ3 тощо не виявило статистично вірогідних відмінностей. Найпоширенішими серед опитаних лікарів та їхніх родичів виявилися хвороби органів травлення (такий діагноз встановили в 19,8 зі 100 опитаних лікарів; 26,9 зі 100 опитаних

зазначили, що такий діагноз мають їхні родичі), хвороби системи кровообігу (18,0 та 52,7 на 100 осіб відповідно), ендокринні хвороби (18,0 та 28,7 на 100 осіб відповідно), хвороби сполучної тканини (12,6 та 16,8 на 100 осіб відповідно), хвороби органів дихання (9,0 та 16,8 на 100 осіб відповідно) та хвороби сечостатевої системи (7,8 та 11,4 на 100 осіб відповідно). Серед родичів лікарів поширеність новоутворень становить 10,2 на 100 осіб. Очевидно, що у цих даних не представлена тяжка інвалідизуюча патологія лікарів, оскільки всі опитані були працездатні. Статистично вірогідні різниці між мешканцями обласних центрів та інших населених пунктів не встановлено.

Таблиця 2. Характеристика ставлення до здоров'я опитаних лікарів, \%

\begin{tabular}{|l|c|c|c|c|c|}
\hline \multicolumn{1}{|c|}{ Група } & $\begin{array}{c}\text { Наявні } \\
\text { НІ3 }\end{array}$ & $\begin{array}{c}\text { Наявні у родичів } \\
\text { НІ3 }\end{array}$ & $\begin{array}{c}\text { Мають сімейного } \\
\text { лікаря }\end{array}$ & $\begin{array}{c}\text { Відвідували лікаря- } \\
\text { спеціаліста }\end{array}$ & Курці \\
\hline А & 58,2 & 82,1 & 94,9 & 86,1 & 16,5 \\
\hline Б & 55,7 & 84,1 & 97,7 & 81,6 & 14,8 \\
\hline Всього & 56,9 & 83,1 & 96,4 & 83,7 & 15,6 \\
\hline
\end{tabular}

Близько 84,0 \% лікарів-респондентів засвідчили, що регулярно зверталися до лікаря-спеціаліста 3 метою профілактичного огляду. Водночас лише близько половини лікарів регулярно відвідували стоматолога, а лікарів-жінок - гінеколога (статистично вірогідну різницю між досліджуваними групами не визначено). До офтальмолога регулярно зверталися 4,2 \% опитаних, до дерматолога, ендокринолога та мамолога - по 2,4\% лікарів.
Обидві групи лікарів високо оцінили актуальність проблеми НІ3 для України та світу, істотно менше - ступінь власного залучення до проблеми, а найнижчим балом була оцінена складність заходів із профрілактики НІ3 (табл. 3): за 10-бальною шкалою (де 1,0 бал означає «Перешкоди відсутні», а 10,0 - «Перешкоди неподоланні») мешканці обласних центрів поставили оцінку 5,5 бала, а інших населених пунктів - 6,3 бала (різниця статистично вірогідна, p=0,036). 
Таблиця 3. Сприйняття проблеми неінфекційних захворювань, рівня персонального залучення та перешкод, бали

\begin{tabular}{|c|c|c|c|c|c|c|c|}
\hline \multicolumn{2}{|c|}{ Група } & $\begin{array}{c}\text { Актуальність } \\
\text { проблеми } \\
\text { НІЗ для } \\
\text { України } \\
\end{array}$ & $\begin{array}{c}\text { Актуальність } \\
\text { проблеми НІ3 } \\
\text { для світу }\end{array}$ & $\begin{array}{c}\text { Актуальність } \\
\text { проблеми } \\
\text { НІЗ для } \\
\text { респондента } \\
\end{array}$ & $\begin{array}{c}\text { Складність } \\
\text { заходів із } \\
\text { лікування } \\
\text { НІ3 } \\
\end{array}$ & $\begin{array}{c}\text { Самооцінка } \\
\text { достатності дій } \\
\text { зі збереження } \\
\text { здоров'я }\end{array}$ & $\begin{array}{c}\text { Складність } \\
\text { заходів із } \\
\text { профрілактики } \\
\text { НІ3* }^{*} \\
\end{array}$ \\
\hline \multirow[t]{2}{*}{$A$} & $X$ & 9,6 & 9,5 & 7,5 & 6,6 & 6,7 & 5,5 \\
\hline & $\mathrm{Me}$ & 10,0 & 10,0 & 8,0 & 7,0 & 7,0 & 5,0 \\
\hline \multirow[t]{2}{*}{5} & $x$ & 9,5 & 9,2 & 7,2 & 7,0 & 6,8 & 6,3 \\
\hline & $\mathrm{Me}$ & 10,0 & 10,0 & 8,0 & 7,5 & 7,0 & 6,5 \\
\hline \multirow{2}{*}{ Всього } & $x$ & 9,6 & 9,4 & 7,4 & 6,8 & 6,8 & 5,9 \\
\hline & $\mathrm{Me}$ & 10,0 & 10,0 & 8,0 & 7,0 & 7,0 & 6,0 \\
\hline
\end{tabular}

Примітка. * - між підгрупами встановлена різниця, статистично вірогідна на рівні p=0,036.

Найбільшу зацікавленість викликали питання про поширеність неінфекційних захворювань в Україні та актуальність проблеми для її громадян (понад 95,0 \% опитаних оцінили її на 8,0 і більше балів 3 10,0, медіана (Ме) - 10,0 балів). Понад половина опитаних оцінила найвищим балом питання стосовно поширеності та актуальності проблеми НІ3 для світу, назвала НІ3 найчастішою причиною смерті в Україні та світі. Опитані лікарі вважали істотним вплив способу життя на розвиток НІ3, а також якість та тривалість життя людини з НІ3 (Ме 9,0 балів) (табл. 4).

Таблиця 4. Оцінка поширених міфів щодо неінфекційних захворювань, бали

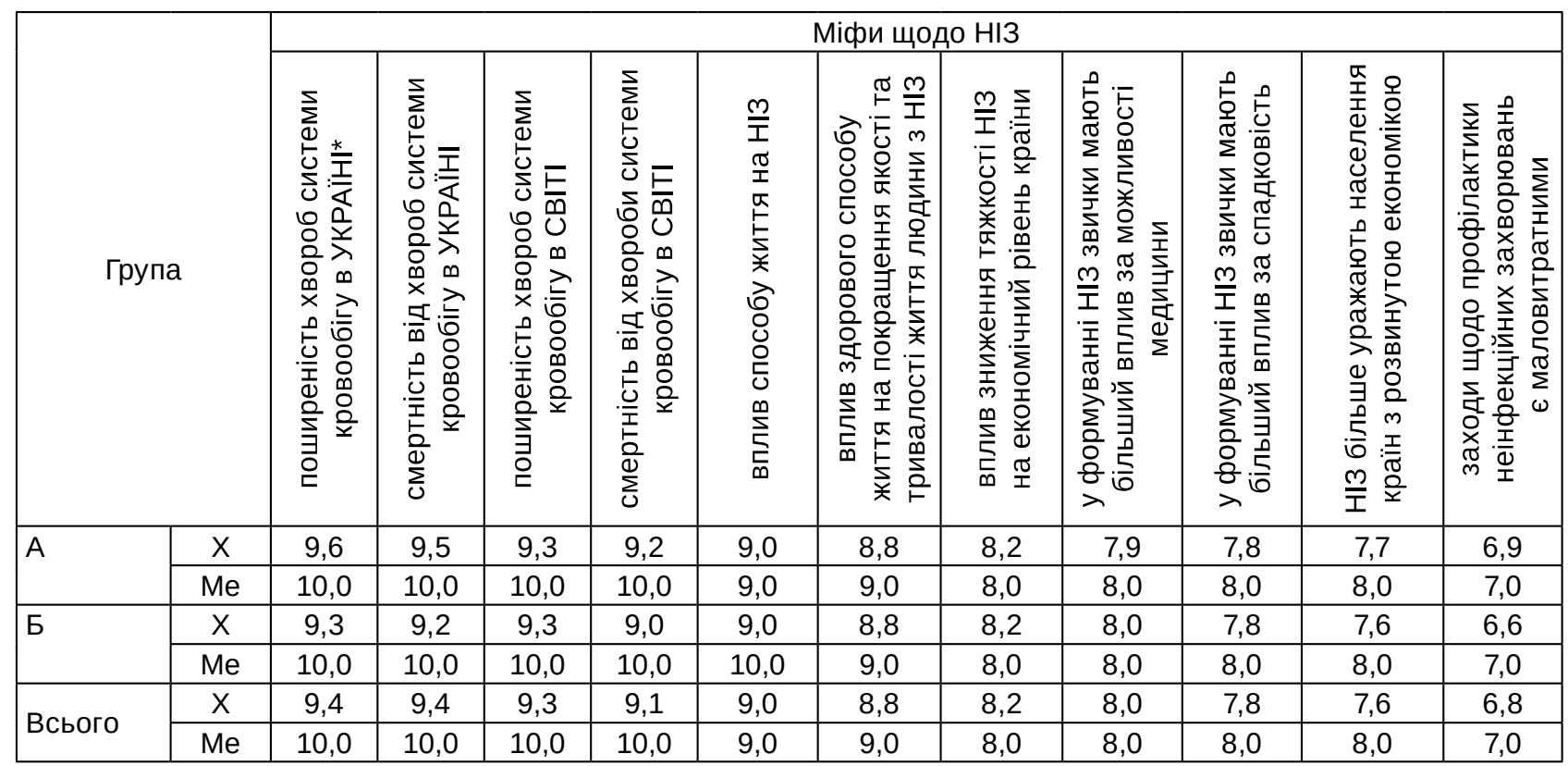

Примітка. * - між підгрупами встановлена різниця, статистично вірогідна на рівні $p=0,043$.

Респонденти по-різному оцінили доступність заходів із профрілактики та лікування НІ3 (Ме 7,0 балів, де 10,0 балів - максимальна доступність). Також лікарі висловили підтримку тези щодо більшої поширеності НІЗ у країнах із розвинутою економікою (Ме 8,0 балів), що не завжди відповідає дійсності.

Відповідальність за здоров'я (табл. 5) лікарі 3 обох підгруп покладають на саму особу (Me 10,0 балів), лікарів (Ме 7,0 балів) та близьке оточення (Ме 7,0 балів), а найменше очікують від волонтерів (Ме 4,0 бали), ВОО3 (Ме 5,0 балів) та преси (Ме 5,0 балів). Важливо, що така висока оцінка впливу самої особи на здоров'я не озна- чає автоматичного здійснення дій, спрямованих на його збереження [1].

Опитані високо оцінили потребу дітей дотримуватися правил здорового способу життя (табл. 6). Чинник дотримання правил безпечного сексу здобув середню оцінку в 9,8 бала за 10-бальною шкалою, а найнижчим балом була оцінена потреба дотримуватися всіх рекомендацій (9,0 балів). Основними механізмами залучення дітей до здорового способу життя (табл. 7) є пояснення (X 7,8 бала, Ме 9,0 балів, де 1,0 бал означає «Не роблю цього», а 10,0 - «Так, щодня») та наведення інформації від лікарів (X 7,1 бала, Ме 8,0 балів). Найменше з цією метою лікарі на- 
водять інорормацію з інтернету або зі зМІ (Me 7,0 і 6,0 балів відповідно). Ці два блоки інформації не містять статистично вірогідних різниць за підгрупами лікарів.

Таблиця 5. Ставлення лікарів до відповідальних за здоров'я осіб, бали

\begin{tabular}{|c|c|c|c|c|c|c|c|c|c|c|c|c|c|}
\hline Гру & & 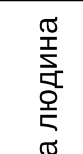 & 荬 & 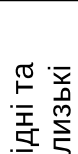 & 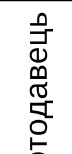 & $\stackrel{\text { O }}{\Sigma}$ & 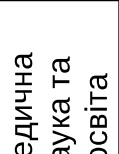 & O̊ & $\begin{array}{l}\frac{\sigma}{T} \\
\frac{\sigma}{0} \\
\frac{\sigma}{\sigma} \\
\frac{\sigma}{2} \\
\frac{\sigma}{2}\end{array}$ & 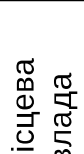 & త్ర & O̊ & 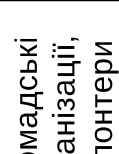 \\
\hline$A$ & $X$ & 9,8 & 7,1 & 6,6 & 5,7 & 5,7 & 5,5 & 5,5 & 5,0 & 5,0 & 4,9 & 4,7 & 4,1 \\
\hline & $\mathrm{Me}$ & 10,0 & 8,0 & 7,0 & 6,0 & 6,0 & 5,0 & 6,0 & 5,0 & 5,0 & 4,0 & 5,0 & 4,0 \\
\hline 5 & $x$ & 9,7 & 6,9 & 6,9 & 6,1 & 6,0 & 5,9 & 5,4 & 5,4 & 5,2 & 5,2 & 5,1 & 4,2 \\
\hline & $\mathrm{Me}$ & 10,0 & 7,0 & 7,5 & 6,0 & 6,5 & 6,0 & 5,0 & 5,0 & 5,0 & 5,0 & 5,0 & 4,0 \\
\hline & $x$ & 9,7 & 7,0 & 6,8 & 5,9 & 5,8 & 5,7 & 5,4 & 5,2 & 5,1 & 5,1 & 4,9 & 4,2 \\
\hline BC & $\mathrm{Me}$ & 10,0 & 7,0 & 7,0 & 6,0 & 6,0 & 6,0 & 5,0 & 5,0 & 5,0 & 5,0 & 5,0 & 4,0 \\
\hline
\end{tabular}

Таблиця 6. Потреба у дотриманні рекомендацій дітьми, бали

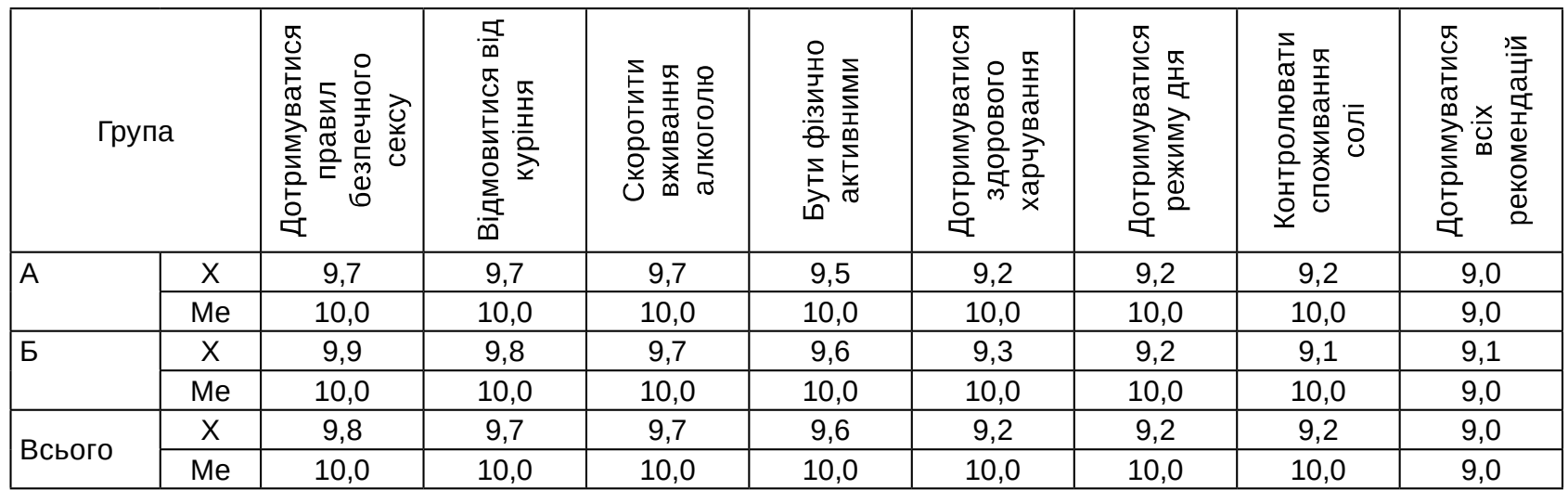

Таблиця 7. Заходи із залучення дитини до здорового способу життя, бали

\begin{tabular}{|c|c|c|c|c|c|c|c|c|}
\hline \multicolumn{2}{|c|}{ Група } & \multirow{2}{*}{$\begin{array}{c}\text { Пояснення } \\
8,1\end{array}$} & \multirow{2}{*}{$\begin{array}{c}\text { Інформація } \\
\text { від лікарів } \\
7,2\end{array}$} & \multirow{2}{*}{$\begin{array}{c}\text { Власний } \\
\text { приклад } \\
7,0\end{array}$} & \multirow{2}{*}{$\begin{array}{c}\text { Приклад } \\
\text { друзів } \\
6,8\end{array}$} & \multirow{2}{*}{$\begin{array}{c}\text { Інфрормація } \\
\text { з наукових } \\
\text { досліджень } \\
6,9\end{array}$} & \multirow{2}{*}{$\begin{array}{c}\text { Інформація } \\
\text { 3 інтернету } \\
6,8\end{array}$} & \multirow{2}{*}{$\begin{array}{c}\text { Iнорормація } \\
\text { зі 3МІ } \\
6,0\end{array}$} \\
\hline$A$ & $x$ & & & & & & & \\
\hline & $\mathrm{Me}$ & 9,0 & 8,0 & 7,0 & 7,5 & 8,0 & 8,0 & 6,0 \\
\hline \multirow[t]{2}{*}{ Б } & $x$ & 7,5 & 6,9 & 6,5 & 6,5 & 6,1 & 6,0 & 5,8 \\
\hline & $\mathrm{Me}$ & 8,0 & 8,0 & 7,0 & 7,0 & 6,5 & 7,0 & 6,0 \\
\hline \multirow{2}{*}{ Всього } & $x$ & 7,8 & 7,1 & 6,7 & 6,6 & 6,5 & 6,4 & 5,9 \\
\hline & $\mathrm{Me}$ & 9,0 & 8,0 & 7,0 & 7,0 & 7,0 & 7,0 & 6,0 \\
\hline
\end{tabular}

Респонденти мали оцінити вплив запропонованих чинників (спеціальність, фрінансовий стан, розпорядок дня, зайнятість тощо) на здоров'я, оцінка 1,0 бал означала «Не сприяють (шкодять) здоров'ю», а 10,0 балів - «Сприяють здоров'ю». Більшість респондентів оцінила всі чинники як сприятливі (табл. 8). На думку опитаних, найбільше сприяє їхньому здоров'ю харчування (Ме 10,0 балів), доступність інфрормації про здоров'я (Ме 9,0 балів) та настрій (Ме 9,0 балів). Найменш сприятливими (чи навіть шкідливими) чинниками є зайнятість (Ме 7,0 балів), екологічна ситуація (Ме 8,0 балів) та місце роботи (Ме 8,0 балів) - ці чинники оцінили як несприятливі 32,3 \%, 27,1 \% та 26,7 \% опитаних відповідно.
Встановлена статистично вірогідна різниця в оцінці підгрупами впливу на здоров'я фрінансового стану та традицій у родині - обидва чинники мешканці обласних центрів вважали менш сприятливими, ніж лікарі, які живуть у решті населених пунктів.

Серед заходів сприяння здоров'ю, таких, як адміністративні заборони, консультування лікарем під час прийому, просвітницькі кампанії, опитані оцінили як ефективний захід - консультування лікарем, централізовані дії (йодування солі), відгуки друзів та просвітницькі кампанії (табл. 9), а решту - як малоефективні. Мешканці обласних центрів істотно вище оцінювали ефективність адміністративних заборон (3,4 бала). 
Таблиця 8. Чинники впливу на поведінку стосовно здоров'я, бали

\begin{tabular}{|c|c|c|c|c|c|c|c|c|c|c|c|c|c|c|}
\hline Гру & & 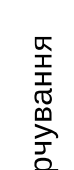 & 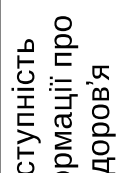 & 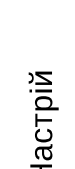 & 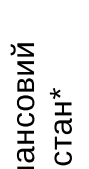 & 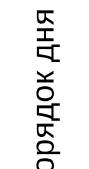 & 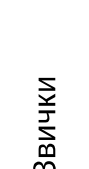 & 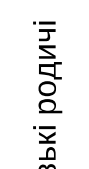 & 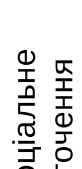 & 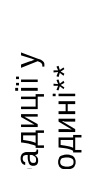 & 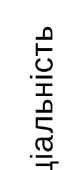 & $\begin{array}{l}\bar{b} \\
\stackrel{0}{0} \\
\stackrel{0}{0} \\
\underline{\omega}\end{array}$ & 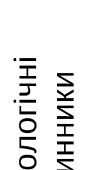 & 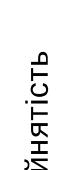 \\
\hline A & $X$ & 8,8 & 8,1 & 8,3 & 7,9 & 8,0 & 7,9 & 7,9 & 7,6 & 7,0 & 7,3 & 7,4 & 7,3 & 6,6 \\
\hline & $\mathrm{Me}$ & 10,0 & 9,0 & 9,0 & 8,5 & 9,0 & 9,0 & 8,0 & 8,0 & 7,0 & 8,0 & 8,0 & 8,0 & 7,0 \\
\hline & $4 \mathrm{H}$ & 8,9 & 12,6 & 12,9 & 21,8 & 14,0 & 19,0 & 18,0 & 21,8 & 27,9 & 22,8 & 24,7 & 29,4 & 35,4 \\
\hline & $x$ & 8,9 & 8,5 & 8,3 & 8,6 & 8,1 & 7,8 & 7,7 & 7,8 & 8,1 & 7,5 & 7,3 & 7,3 & 7,0 \\
\hline Б & $\mathrm{Me}$ & 10,0 & 9,0 & 9,0 & 9,0 & 9,0 & 9,0 & 8,0 & 9,0 & 9,0 & 8,0 & 8,5 & 8,5 & 7,0 \\
\hline & $4 \mathrm{H}$ & 3,4 & 6,7 & 16,0 & 6,8 & 12,6 & 20,4 & 15,8 & 18,1 & 14,8 & 22,7 & 28,4 & 25,0 & 29,5 \\
\hline & $x$ & 8,9 & 8,3 & 8,3 & 8,3 & 8,1 & 7,8 & 7,8 & 7,7 & 7,6 & 7,4 & 7,3 & 7,3 & 6,8 \\
\hline Всього & Mt & 10,0 & 9,0 & 9,0 & 9,0 & 9,0 & 9,0 & 8,0 & 8,0 & 8,0 & 8,0 & 8,0 & 8,0 & 7,0 \\
\hline & $4 \mathrm{H}$ & 6,0 & 9,6 & 14,5 & 13,9 & 13,3 & 19,8 & 16,9 & 19,9 & 21,0 & 22,8 & 26,7 & 27,1 & 32,3 \\
\hline
\end{tabular}

Примітка. 1-5 балів - відсутність впливу або несприятливий вплив; 6-10 балів - сприятливий вплив; * між підгрупами встановлена різниця, статистично вірогідна на рівні $p=0,039$; * - між підгрупами встановлена різниця, статистично вірогідна на рівні $p=0,003$.

Таблиця 9. Оцінка ефективності заходів сприяння здоров'ю, бали

\begin{tabular}{|c|c|c|c|c|c|c|c|c|}
\hline & & 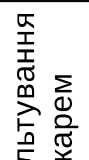 & 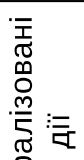 & $\begin{array}{l}\frac{m}{m} \\
\frac{a}{\bar{c}} \\
\frac{\sqrt{x}}{x}\end{array}$ & 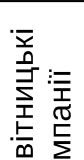 & 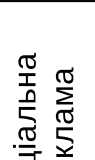 & $\begin{array}{l}0 \\
\sum_{1}^{0} \\
\exists\end{array}$ & 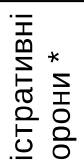 \\
\hline$A$ & Mean & 4,2 & 4,0 & 3,6 & 3,6 & 3,5 & 3,4 & 3,4 \\
\hline & Median & 4,0 & 4,0 & 4,0 & 4,0 & 3,0 & 3,0 & 3,0 \\
\hline 5 & Mean & 4,1 & 3,7 & 3,7 & 3,5 & 3,3 & 3,4 & 3,1 \\
\hline & Median & 4,0 & 4,0 & 4,0 & 3,5 & 3,0 & 3,0 & 3,0 \\
\hline & Mean & 4,2 & 3,8 & 3,7 & 3,5 & 3,4 & 3,4 & 3,2 \\
\hline Всього & Median & 4,0 & 4,0 & 4,0 & 4,0 & 3,0 & 3,0 & 3,0 \\
\hline
\end{tabular}

Примітка. 1 бал - вкрай неефективні; 2 - неефективні; 3 - малоефективні; 4 - ефрективні; 5 - високоефективні; * - між підгрупами встановлена різниця, статистично вірогідна на рівні $p=0,039$.

За демограсрічними та соціальними показниками картина передбачувана: наближеність до закладів освіти, більша кількість спеціалізованих та високоспеціалізованих закладів медичної допомоги, а також приватних закладів зумовлюють переважну більшість знайдених відмінностей, зокрема й істотно нижче володіння та використання у професійній діяльності англійської мови серед респондентів групи Б.

Водночас респонденти обох підгруп оцінили своє підключення до інтернету як таке, що дає можливість практично вільного користування послугами мережі (9,6 бала у групі А та 9,1 бала у групі $Б, ~ p=0,009)$.

Респонденти підгруп не продемонстрували вірогідних різниць за характеристиками ставлення до здоров'я (табл. 2). Привертає увагу те, що у захворюваності лікарів першість посідають хво- роби органів травлення. 3 одного боку, це зумовлено особливостями опитаних лікарів, оскільки анкетування працездатних осіб істотно зменшує вірогідність наявності у них тяжкої інвалідизуючої патології. Водночас таку поширеність хвороб органів травлення необхідно враховувати під час розробки профрілактичних програм, спрямованих на працездатне населення, лікарів зокрема.

Хоча 96,4 \% опитаних відповіли, що мають сімейного лікаря, рівень звернень до профільних спеціалістів для проходження профілактичних оглядів, зокрема лікарів-стоматологів (51,5 \%), видається недостатнім. Ще однією сорерою для удосконалення $€$ посилення образу лікаря як рольової моделі стосовно здоров'я, що передбачає подальшу відмову від шкідливих звичок (зараз курцем є кожен шостий лікар). 
Обидві групи респондентів виявили високу поінформованість про важливість проблеми НІ3 для України та світу і дещо нижчу - про вплив звичок на розвиток НІ3, їхній внесок у цю групу патологій порівняно 3 можливостями медицини та генетичними чинниками. Опитані лікарі вважали профрілактичні заходи досить складними та витратними, особливо це актуальне для респондентів групи Б.

Незважаючи на декларування персональної відповідальності кожної людини за власне здоров'я, респонденти поклали істотну частку відповідальності на лікарів, рідних, роботодавця, органи влади тощо (табл. 5). Спричинене цим розмивання відповідальності може істотно гальмувати здійснення прикладної діяльності, спрямованої на підтримку здоров'я, і потребує детальнішого вивчення.

Лікарі з обох підгруп продемонстрували високу прихильність до дотримання засад здорового способу життя дітьми та досить високу готовність говорити 3 ними про це. Сферою потенційного удосконалення $€$ посилення прикладної компоненти залучення до ЗСЖ: посилання на власний приклад та приклад друзів.

Найбільш несприятливими для здоров'я чинниками опитані лікарі назвали зайнятість, екологічну ситуацію та місце роботи: так вважає близько третини кожної підгрупи. Встановлена статистично вірогідна різниця в оцінці впливу фінансового стану та сімейних традицій на здоров'я: респон- денти групи Б вважали вплив цих чинників більш сприятливим.

Назагал лікарі вважали заходи сприяння здоров'ю, такі, як просвітницькі кампанії, соціальна реклама тощо малоефективними. Найменш ефективним серед запропонованих лікарі назвали адміністративні заборони, причому респонденти групи Б оцінили їх ефективність вірогідно нижче за групу A.

\section{Висновки}

При порівнянні оцінки респондентами популярних тверджень щодо НІ3, осіб та інституцій, що несуть відповідальність за здоров'я людини, поглядів на ефективність профрілактичних заходів, впливу на здоров'я окремих чинників оточення не виявлено значних відмінностей між лікарями, які працюють у м. Києві та обласних центрах, та лікарями, які працюють в інших населених пунктах.

Респонденти обох груп продемонстрували досить високу поінформованість про заходи 3 профілактики НІ3 та визнавали необхідність дотримання здорового способу життя, водночас не завжди така теоретична підтримка супроводжується практичними діями, спрямованими на підтримку здоров'я.

Перспективи подальших досліджень. Переоцінка респондентами складності та вартості заходів із профілактики НІ3 свідчить про необхідність більш детального та доступного представлення спектра можливих заходів сприяння здоров'ю (використання сходів замість ліфрта) для ефективнішої профрілактики.

\section{Список літератури}

1. Балашов К. В. Відповідальність за здоров'я та куріння: погляд лікарів / К. В. Балашов, В. I. Кащенко // World science: problems, prospects and innovations : Abstracts of the 5th International scientific and practical conference, 27-29 January 2021. - Toronto, Canada : Perfect Publishing. - 2021. - P. 290-294.

2. Балашов К. В. Громадське здоров'я та культура: точки дотику / К. В. Балашов // Modern science: problems and innovations : Abstracts of the 3rd International scientific and practical conference. - Stockholm : SSPG Publish. - 2020. P. 74-79. DOI: 10.6084/m9.figshare.12652880.v1.

3. Знаменська М. А. Медико-соціальне обґрунтування системи комунікацій в охороні здоров'я : автореср. дис. на здобуття наук. ступеня доктора медичних наук : 14.02.03 / М. А. Знаменська. - К., 2015. - 20 с.

4. Концептуальна рамка психографрічних досліджень у сфері профрілактики неінфекційних захворювань / К. В. Балашов, Г. О. Слабкий, О. П. Гульчій, Н. М. Захарова // Український медичний часопис. - 2020. - № 5 (2). C. 139.

5. Abraham T. The price of poor pandemic communication / T. Abraham // British Medical Journal. - 2010. - P. 1307.

6. Awareness and use of evidence-based medicine information among patients in Croatia: a nation-wide cross-sectional study / D. Nejašmić, I. Miošić, D. Vrdoljak [et al.] // Croat. Med. J. - 2017.- P. 300-301.

7. Carey J. W. Communication as Culture: Essays on Media and Society.- Psychology Press. 1992.

8. Eysenbach G. Internet Health Information Seeking and the Patient-Physician Relationship: A Systematic Review I G. Eysenbach // J. Med. Internet. Res. - 2017. - P. 9.

9. Improving Medical Decision Making and Health Promotion through Culture-Sensitive Health Communication: An Agenda for Science and Practice / C. Betsch, R. Bohm, C.O. Airhihenbuwa [et al.] // Medical Decision Making. - 2016. - P. 811-833. 10. Social and cultural factors behind community resistance during an Ebola outbreak in a village of the Guinean Forest region, February 2015: a field experience. / A. Carrión, T. Martín Derrough, P. Honomou [et al.] // International Health. 2016 (8). - P. 227-229.

11. Tonsaker T. Health information on the Internet. Gold mine or minefield? / T. Tonsaker, G. Bartlett, C. Trpkov // Can. Fam. Physician. - 2014. - P. 407-408. 


\section{References}

1. Balashov, K.V., \& Kashchenko, V.I. (2021). Vidpovidalnist za zdorovia ta kurinnia: pohliad likariv [Responsibility for health and smoking: the view of doctors]. World science: problems, prospects and innovations. Abstracts of the $5^{\text {th }}$ International scientific and practical conference. Toronto, Canada: Perfect Publishing [in Ukrainian].

2. Balashov, K.V. (2020). Hromadske zdorovia ta kultura: tochky dotyku [Public health and culture: points of contact]. Modern science: problems and innovations. Abstracts of the $3^{\text {rd }}$ International scientific and practical conference. (pp. $74-$ 79). Stockholm: SSPG Publish. DOI: 10.6084/m9.figshare.12652880.v1 [in Ukrainian].

3. Znamenska, M.A. (2015). Medyko-sotsialne obgruntuvannia systemy komunikatsii v okhoroni zdorovia. [Medico-social substantiation of the communication system in health care]. Extended abstract of Doctor's thesis. Kyiv [in Ukrainian].

4. Balashov, K., Slabkyi, H., Hulchiy, O., \& Zakharova, N. (2020). Kontseptualna ramka psykhohrafichnykh doslidzhen u sferi profilaktyky neinfektsiinykh zakhvoriuvan [Conceptual framework of psychographic research in the field of prevention of non-communicable diseases]. Ukrayinskyi medychnyi chasopys - Ukrainian Medical Journal, 5 (139) . DOI: 10.32471/ umj.1680-3051.139.191002 [in Ukrainian].

5. Abraham, T. (2010). The price of poor pandemic communication. British Medical Journal, 1307.

6. Nejašmić, D., Miošić, I., Vrdoljak, D., Permozer Hajdarović, S., Tomičić, M., \& Gmajnić, R. (2017). Awareness and use of evidence-based medicine information among patients in Croatia: a nation-wide cross-sectional study. Croat. Med. J. 58, 4 , 300-301.

7. Carey, J.W. (1992). Communication as Culture: Essays on Media and Society. Psychology Press.

8. Eysenbach, G. (2017). Internet Health Information Seeking and the Patient-Physician Relationship: A Systematic Review. J. Med. Internet. Res., 19(1), 9.

9. Betsch, C., Bohm, R., Airhihenbuwa, C., Butler, R., Chapman, G., \& Haase, N. (2016). Improving Medical Decision Making and Health Promotion through Culture-Sensitive Health Communication: An Agenda for Science and Practice. Medical Decision Making , 811-833.

10. Carrión Martín, A., Derrough, T., Honomou, P., Kolie, N., Diallo, B., \& Koné, M. (2016). Social and cultural factors behind community resistance during an Ebola outbreak in a village of the Guinean Forest region, February 2015: a field experience. International Health, 227-229.

11. Tonsaker, T., Bartlett, G., \& Trpkov, C. (2014). Health information on the Internet. Gold mine or minefield? Can. Fam. Physician, 60(5), 407-408.

\section{ATTITUDE OF DOCTORS TOWARDS PREVENTION OF NON-INFECTIOUS DISEASES - ADMINISTRATIVE-TERRITORIAL INFLUENCE FACTOR}

K. V. Balashov

P. Shupyk National Healthcare University of Ukraine, Kyiv, Ukraine

Purpose: to characterize the beliefs and activities of doctors regarding health and to determine the behavioral characteristics of subgroups of doctors working in the capital / regional centers or in other settlements.

Materials and Methods. 167 doctors representing all macro-regions of Ukraine were interviewed: the levels of awareness about NCD myths, the locus of control, views on the effectiveness of prevention measures, the impact on health of certain environmental factors. The results were evaluated on the basis of descriptive statistics, the statistical probability of the difference was determined by methods of pairwise comparison (with Bonferroni correction) and analysis of variance.

Results. Comparison of respondents' assessments showed few differences between doctors working in Kyiv and regional centers (group A) and doctors working in other settlements (group B). Physicians show a high level of awareness about NCD prevention measures, but do not always take practical measures to maintain health. In the opinion of the physicians in both subgroups, the own individual, physicians, and relatives are the most responsible for the person's health. Respondents praised the need for children to follow the rules of a healthy lifestyle, especially - the rules of safe sex. Residents of regional centers consider the impact on the health of their financial situation and family traditions to be less favorable than doctors living in other settlements.

Conclusions. Comparison of respondents' assessment of popular statements about NCDs, individuals, and institutions responsible for human health, perceptions on the effectiveness of prevention measures, the impact on the health of individual environmental factors did not show significant differences between doctors working in Kyiv and regional centers ( group A) and doctors working in other settlements (group B). Respondents overestimate the complexity of NCD prevention measures, which indicates the need for a more detailed and accessible presentation of the range of possible health promotion measures for more effective prevention.

KEY WORDS: non-communicable diseases; healthy lifestyle; continuous professional development; social marketing.

Рукопис надійшов до редакції 24.12.2020 p.

\section{Відомості про автора:}

Балашов Костянтин В'ячеславович - завідувач відділу комунікацій Національного університету охорони здоров'я України імені П. Л. Шупика. 